\title{
PROPOSTA DE DESENVOLVIMENTO DE EMPUNHADURA PERSONALIZADA PARA USUÁRIOS COM MAL DE PARKINSON
}

\author{
Stefan von der Heyde Fernandes \\ Universidade Federal do Rio Grande do Sul - UFRGS \\ stefanufrgs@gmail.com \\ Fábio Pinto da Silva \\ Universidade Federal do Rio Grande do Sul - UFRGS \\ fabio.pinto@ufrgs.br \\ Tânia Luisa Koltermann da Silva \\ Universidade Federal do Rio Grande do Sul - UFRGS \\ tania.silva@ufrgs.br
}

\begin{abstract}
Resumo: O presente trabalho propõe-se a conhecer as dificuldades reais de um usuário com a doença de mal de Parkinson, no sentido de criar um produto que auxilie esses indivíduos em suas atividades da vida diária. $\mathrm{O}$ objetivo deste trabalho é, através das técnicas de digitalização tridimensional e usinagem $\mathrm{CNC}$, desenvolver produtos que atendam as necessidades específicas desses usuários que possuem dificuldades motoras devido aos tremores involuntários. Foi realizado o processo de produção de uma pega antropomórfica personalizada para um usuário acometido pelo mal de Parkinson e avaliou-se seu desempenho em uma tarefa de barbear-se. Concluiu-se que produtos personalizados podem influenciar positivamente a vida do usuário, favorecendo o cumprimento de tarefas anteriormente impossíveis de serem realizadas.
\end{abstract}

Palavras-chave: Digitalização tridimensional, Usinagem CNC, Mal de Parkinson

Abstract: This study aims to know the real difficulties of a carrier of Parkinson's disease in order to create a product that assists these individuals in their daily activities. The objective of this work is, through the techniques of three-dimensional scanning and CNC machining, develop products that meet the specific needs of those users who have motor difficulties in the hand due to involuntary tremors. The process of producing a customized anthropomorphic handle for a carrier of Parkinson's disease was made and we evaluated their performance on a task to shave. We 
conclude that personalized products can positively influence the user's life, encouraging the fulfillment of previously impossible tasks to be performed.

Keywords: three-dimensional scanning, CNC machining, Parkinson's disease.

\section{INTRODUÇÃO}

A carência de produtos no mercado específicos para pessoas com deficiência é notória, pois estes produtos, muitas vezes, restringem o uso a apenas este público, dificultando suas possiblidades de produção e distribuição. Ao mesmo tempo, o processo de personalização pode ser uma alternativa para a produção de novos produtos, tendo em vista que é crescente o surgimento de tecnologias que tornam a produção mais flexível e versátil. Impressoras 3D, máquinas de usinagem por controle numérico (CNC) e a digitalização tridimensional são exemplos de tecnologias recentes que podem ser aplicadas à tecnologia assistiva e favorecer os indivíduos com deficiências.

Um potencial público são os Parkinsonianos, indivíduos com mal de Parkinson, uma doença degenerativa do sistema nervoso central. A qualidade de vida dessas pessoas diminui muito quando suas atividades diárias não são mais cumpridas devido aos tremores involuntários provenientes da doença, ainda, estas limitações físicas geram uma sensação de impotência, podendo ocasionar depressão (REIS, 2012). Por isso, o design tem fundamental importância no papel de projetar novos produtos que proporcionem uma melhor qualidade de vida para estes usuários.

Através de metodologia de desenvolvimento de produto e técnicas inovadoras de produção é possível produzir artefatos que auxiliem essa minoritária população de usuários, e, assim, trazer um impacto relevante em suas vidas.

Neste sentido, o objetivo deste trabalho é, através das técnicas de digitalização tridimensional e usinagem CNC (Controle Numérico Computadorizado), propor o desenvolvimento de produtos personalizados que atendam às necessidades específicas de usuários com dificuldades motoras.

Para o melhor aprofundamento do conhecimento no trabalho, buscou-se na literatura os efeitos e impactos do mal de Parkinson na vida cotidiana do acometido pela doença, questões ergonômicas da empunhadura para diferentes usuários, e a aplicação de novas tecnologias que proporcionassem o desenvolvimento de um novo produto para estes indivíduos. Estes temas são apresentados nos capítulos a seguir.

\section{DOENÇA DE PARKINSON}

A doença de Parkinson, também conhecida como mal de Parkinson se caracteriza pela desordem progressiva que acontece no movimento, consequência de uma disfunção de alguns neurônios secretores, que são responsáveis pelo controle e ajustamento das transmissões dos comandos conscientes, que são enviados para eles do córtex cerebral (LEITE, 2012).

Essa é uma doença degenerativa do sistema nervoso central do indivíduo, isto é, ocorre morte celular dos neurônios responsáveis pela produção de dopamina. 0 progresso dos sintomas da doença de Parkinson é, na maioria dos casos, lenta, no entanto, essa progressão de sintomas pode variar bastante de caso para caso (LEITE, 2012). Por isso, os primeiros sintomas da doença de Parkinson têm início de modo 
quase imperceptível e progridem lentamente, o que faz com que o próprio paciente, ou seus familiares, não consigam identificar o início preciso das primeiras manifestações. O primeiro sinal pode ser uma sensação de cansaço ou mal estar no fim do dia. A caligrafia pode se tornar menos legível ou diminuir de tamanho, a fala pode se tornar mais monótona e menos articulada. O paciente frequentemente torna-se deprimido sem motivo aparente. Podem ocorrer lapsos de memória, dificuldade de concentração e irritabilidade. Dores musculares são comuns, principalmente na região lombar (LEITE, 2012).

Reis (2012) explica que o tremor é, geralmente, o primeiro sintoma a ser notado pelo paciente e acomete primeiramente um dos lados do corpo, usualmente uma das mãos. Segurar um objeto ou ler um jornal podem se tornar atividades árduas. No início, os sintomas da doença de Parkinson podem afetar apenas um lado do corpo. Mais tarde, frequentemente, ambos os lados são afetados. Em geral, os sintomas mudam com o passar do tempo.

Os principais sintomas da doença são a rigidez dos músculos do corpo; bradicinesia, que é a dificuldade em iniciar algum movimento, causando problemas para se levantar de cadeiras e de camas; alteração no equilíbrio, em que a pessoa anda com a postura levemente curvada para frente; determinados movimentos involuntários automáticos são gradualmente abolidos, como, por exemplo, piscar os olhos (REIS, 2012).

A doença de Parkinson dificulta ao indivíduo, principalmente, as atividades da vida diárias, as AVDs, ou seja, aquelas atividades fundamentais para a sobrevivência, como, por exemplo, comer, manter-se aquecido, manter higiene pessoal, cozinhar, fazer compras, realizar serviços domésticos, etc. (HAGERDORN, apud. RIBEIRO, 2001). Abotoar-se, amarrar os cadarços, utilizar talheres nas refeições, barbear-se, dirigir automóveis e até mesmo escrever tornam-se tarefas muito árduas.

Quando um indivíduo não pode atender suas AVDs, por não possuir certo nível de habilidade ou capacidade para realizar tal tarefa, algum tipo de assistência é requerida. Isto pode trazer frustrações, prejudicar a autoestima e reduzir a qualidade de vida do indivíduo. Por isso, é eminente a importância de artefatos que auxiliem pessoas com doença de Parkinson para melhoria da qualidade de vida dos pacientes.

Este trabalho busca desenvolver uma proposta de produto que minimize as dificuldades encontradas pelos parkinsonianos através de uma pega personalizada que se adapte a mão do usuário. Conforme explicitado, os tremores nas mãos dificultam tarefas simples do dia-a-dia, o manejo fino de produtos, por exemplo, torna-se praticamente impossível e, com isso, o paciente se limita em suas atividades, aumentando a possibilidade de depressão.

\section{ANTROPOMETRIA DA EMPUNHADURA}

A mão possui diversas terminações nervosas e músculos que possibilitam o manejo de versáteis maneiras. lida (1998) define manejo como a forma particular de controle, onde há um predomínio dos dedos e da palma das mãos, pegando, prendendo ou manipulando algum objeto. O manejo, portanto, torna a mão uma das ferramentas mais complexas do corpo humano, sendo versátil e sensível (NAPIER, 1983. apud IIDA 1998). 
Segundo, lida (1998) o manejo pode ser classificado, de forma geral, em dois tipos básicos, o manejo fino e o manejo grosseiro. O manejo fino é caracterizado como:

“[...] é executado com as pontas dos dedos. É chamado também de manejo de precisão. Os movimentos são transmitidos principalmente pelos dedos, enquanto a palma da mão e o punho permanecem relativamente estáticos. Esse tipo de manejo caracteriza-se pela grande precisão e velocidade, com pequena força transmitida nos movimentos. Exemplos: escrever a lápis, enfiar linha na agulha, sintonizar o rádio". (IIDA, 1998. p. 243).

Já o manejo grosseiro é geralmente utilizado quando não há a necessidade de precisão e velocidade, como define o autor:

"O manejo grosseiro ou de força é executado com o centro da mão. Os dedos têm a função de prender, mantendo-se relativamente estáticos, enquanto os movimentos são realizados pelo punho e braço. Em geral, transmite força maiores, com velocidade e precisão menores que o manejo fino. Exemplos: serrar, martelar, capinar". (IIDA, 1998. p. 243).

Para os Parkinsonianos, como visto anteriormente, o manejo fino se torna inviável devido aos tremores musculares involuntários provenientes da doença. Desta forma, atividades simples, como abotoar uma camisa, fazer a barba ou até mesmo amarrar os sapatos são de extremo esforço.

Estes usuários, portanto, necessitam de produtos que auxiliem suas tarefas, substituindo o manejo fino pelo manejo grosseiro, através de pegas maiores e adaptações nas empunhaduras. Desta forma, realizou-se uma busca na literatura para identificar qual a melhor forma de empunhadura existente, qual o diâmetro ideal no manejo grosseiro e qual a pega mais confortável.

Muitos autores já realizaram estudos para avaliar o conforto das pegas e qual o seu diâmetro ideal. Grant, Habes e Steward (1992) analisaram a influência do diâmetro das pegas na redução do esforço manual. Através de um estudo em laboratório, os autores puderam calcular com sensores eletromiográficos de superfície a tensão gerada pelo esforço dos músculos da mão.

Pheasant \& O'Neill (1975 apud. IIDA, 1998) também realizaram esse tipo de estudo através de um cone de variação contínua do diâmetro, para determinar o conforto subjetivo da pega, e chegaram ao valor médio de 3,2 centímetros para o diâmetro que apresenta maior conforto. Segundo lida (1998) esta medida é o diâmetro recomendado para o projeto de cabos de ferramentas manuais e também nos balaústres dos veículos coletivos.

Tilley (2005) afirma que o desenho de empunhaduras deve ter um diâmetro ideal na faixa de 3,2 a 3,8 centímetros, independentemente do sexo do usuário. Ayoub e Lo Presti (1971 apud KONG, FREIVALDS, KIM. 2004) também realizaram um estudo para determinar qual diâmetro de pega seria "excelente" em uma tarefa de trabalho simulado. Dentre as pegas de diâmetro 3,$2 ; 3,8 ; 5,1 ;$ e 6,4 , eles concluíram que o diâmetro de 3,8 centímetros seria o ideal para atividades manuais, por ser menos fatigante, embora houvesse poucas mudanças na atividade.

Grant, Habes e Steward (1992) concluíram que é praticamente impossível indicar um diâmetro ideal único, que seja ótimo para todos os usuários em todos os contextos. Além disso, é necessário considerar o tamanho da mão do usuário em 
relação ao tamanho da pega. Este pode ser um dos motivos pelo qual outros pesquisadores encontraram faixas distintas para o tamanho ideal de pega.

É possível perceber que não há uma unanimidade na literatura com relação ao diâmetro ótimo para a empunhadura, porém, todos concordam que o nível de conforto está relacionado à capacidade de apreensão da mão no objeto, ou seja, quanto maior a superfície da mão for preenchida pela pega, maior será seu conforto.

lida (1998) indica a pega antropomorfa, a qual apresenta maior superfície de contato, permite maior firmeza de pega, transmissão de maiores forças, com concentração menor de tensões em relação aos outros tipos de pega, como, por exemplo, a pega geométrica. $O$ autor ressalta, porém, que pode ser mais fatigante em um trabalho prolongado, pois limita o manejo a uma ou duas posições.

Este referencial teórico serviu para que a pega projetada, mesmo que antropomórfica, seguisse as recomendações ergonômicas corretas, e, assim, evitasse desconforto do usuário. Neste trabalho, utilizou-se inicialmente um cilindro de massa de modelar de quatro centímetros de diâmetro para ser conformado à mão do usuário. O capitulo a seguir explicita de forma mais detalhada como foi conduzido o processo de desenvolvimento desta pega.

\section{MATERIAIS E MÉTODOS}

Para o processo de desenvolvimento desse trabalho, buscaram-se como referência as ferramentas projetuais extraídas da metodologia de Löbach (2001). Segundo o autor, todo processo de design é tanto um processo criativo como um processo de solução de problemas, e, por isso, deve seguir o método identificado como: existe um problema que pode ser bem definido; reúnem-se informações sobre o problema, que são analisadas e relacionadas criativamente entre si; criam-se alternativas de soluções para o problema, que são julgadas segundo critérios estabelecidos; desenvolve-se a alternativa mais adequada. Neste trabalho, foram contempladas as três primeiras fases de desenvolvimento de projeto propostas por Löbach (2001), respectivamente: fase de preparação; fases de alternativas do problema; e fase de avaliação da alternativa selecionada.

\subsection{Fase de preparação}

A fim de desenvolver um produto personalizado, a análise do problema foi realizada em uma entrevista não estruturada com o usuário parkinsoniano. Analisaram-se quais as principais dificuldades motoras em suas atividades diárias, e listaram-se quais as tarefas que Ihe exigiam maior esforço e apresentavam maior dificuldade. As três atividades elencadas foram barbear-se, usar os talheres nas refeições e por fim abotoar as calças. Decidiu-se, portanto, que a delimitação do problema proposto seria a tarefa de barbear-se, e a definição do objetivo de projeto seria produzir um produto que proporcionaria maior conforto ao usuário na tarefa de barbear o rosto.

\subsection{Alternativas do problema}

Após ser delimitado o problema de projeto, foram geradas algumas alternativas que pudessem proporcionar a personalização em massa de um produto voltado para este público. Idealizou-se, desta forma, um processo produtivo que tornasse viável a 
produção de empunhaduras específicas para cada indivíduo. A Figura 1 apresenta o esquema das três etapas de produção necessárias para a produção do produto.

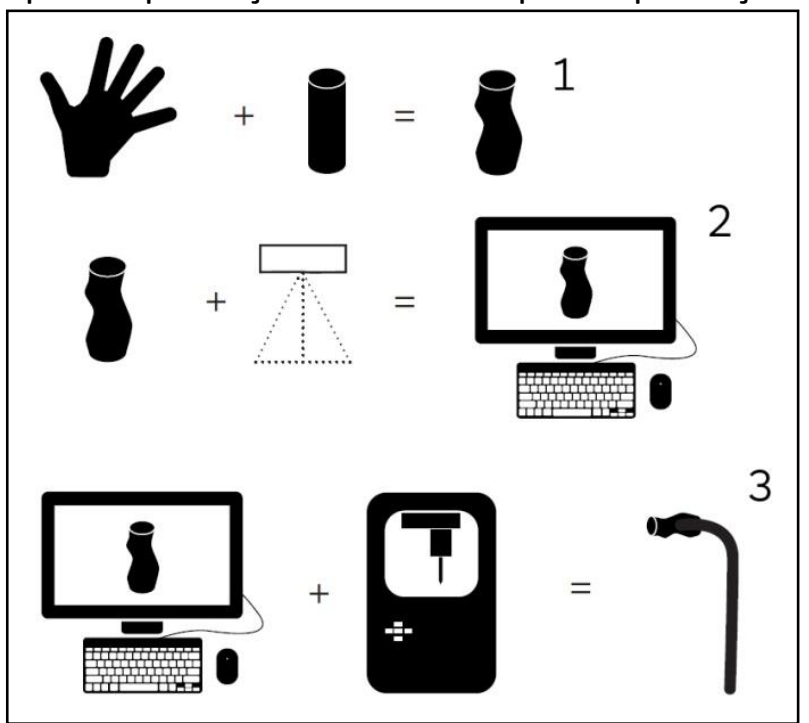

Figura 1 - Representação do processo de produção proposto Fonte: Autor

\subsubsection{Conformação da massa de modelar}

Na primeira etapa, o usuário com deficiência motora pressionou um material maleável (massa de modelar) que se deforma mecanicamente a fim de se moldar a partir da forma da mão. Assim, este material possui o volume antropomórfico ideal para o manejo do usuário. Porém, devido às propriedades mecânicas de uma massa de modelar não é possível que seja produzido um produto com este material. Desta forma, é necessário adquirir um modelo virtual a partir do modelo físico, para que posteriormente possa ser produzido em outro material. A massa de modelar utilizada possuía quatro centímetros de diâmetro e 15 centímetros de altura.

\subsubsection{Digitalização Tridimensional do material}

A partir da massa de modelar já pressionada, foi feita a digitalização tridimensional deste material para que este pudesse ser analisado e editado em software CAD. Este processo, denominado engenharia reversa, proporciona que o projetista adquira um modelo virtual idêntico ao modelo físico construído.

\subsubsection{Produção do produto em novo material}

Por fim, após a edição em software CAD, foi possível produzir o produto de diferentes maneiras. Por se tratar de um produto único personalizado, alguns processos de fabricação tornam-se inviáveis tanto financeiramente quanto em questões de tempo. Por isso, optou-se pela usinagem em CNC para a fabricação da empunhadura.

\subsection{Avaliação da alternativa do problema}

A última etapa deste trabalho consiste em avaliar a solução encontrada na prática, ou seja, foi solicitado que o usuário realizasse a tarefa de se barbear com o produto desenvolvido. Depois de realizada a atividade, foi questionado ao usuário parkinsoniano se aquela empunhadura tinha lhe proporcionado melhorias na tarefa. 


\subsection{Digitalização tridimensional a laser}

A digitalização tridimensional visa à obtenção de modelos virtuais a partir de modelos físicos em um processo inverso à engenharia convencional. Esta técnica é comercialmente conhecida como Engenharia Reversa (SILVA, 2006). Atualmente, existem diversos sistemas de digitalização 3D, sendo eles divididos entre sistemas com contato e sistemas sem contato. Optou-se pelo uso de um sistema de digitalização sem contato, tendo em vista algumas das desvantagens encontradas nos sistemas com contato, tais como a limitação de uso em superfícies que se deformem com o contato e a velocidade do processo. Segundo Freitas (2006) alguns exemplos de digitalização sem contato são: triangulação por Laser, triangulação por cores, fotogrametria por conjuntos de câmeras CCD, fotogrametria por fotografias digitalizadas, tomografia computadorizada, luz infravermelha com CCD linear e sensor conoscópico a Laser.

Utilizou-se para o presente trabalho o método de digitalização a laser por holografia conoscópica. Silva (2006) explica o funcionamento de captação do laser da seguinte maneira:

\footnotetext{
"O cabeçote de digitalização conoscópico consiste na emissão, através de um diodo, de um feixe de Laser, o qual é refletido por um divisor de feixe e incide pontualmente sobre a peça a ser medida. A luz dispersada retorna da peça, passa através do divisor de feixe, por um cristal birrefringente e é detectada pelo sensor CCD (Dispositivo de Carga Acoplado). [...] O cristal birrefringente modifica diferentemente a velocidade de cada raio de luz de acordo com seu ângulo, criando um padrão de franjas com alto contraste no detector CCD. Uma vez que o ângulo do raio de luz é a função da distância entre um plano de referência e o ponto de Laser projetado no objeto, esta distância pode ser então determinada pela análise das características do padrão criado. A relação entre o sinal no detector CCD e a distância dos objetos é determinada por um processo preciso de calibração realizado para cada lente objetiva utilizada" (SILVA, 2006. p.72).
}

Foi utilizado o scanner tridimensional a Laser, marca Tecnodrill, modelo Digimil 3D, instalado nas dependências do Laboratório de Design e Seleção de Materiais da Universidade Federal do Rio Grande do Sul (UFRGS). Este equipamento possui dois cabeçotes, um para usinagem e outro para digitalização, sendo possível ser utilizado tanto como fresadora quanto como scanner tridimensional a laser. Através do CNC, 0 equipamento move o laser nos eixos $X$ e $Y$ enquanto, ao mesmo tempo, o cabeçote laser capta a altura no eixo $Z$. O resultado é um arquivo de texto com milhares de pontos da superfície do objeto descrito em coordenadas $(x, y, z)$, denominado nuvem de pontos. No processo de digitalização seguiram-se os procedimentos para digitalização tridimensional sugerido por Silva (2006), como apresentado no fluxograma da Figura 2. 


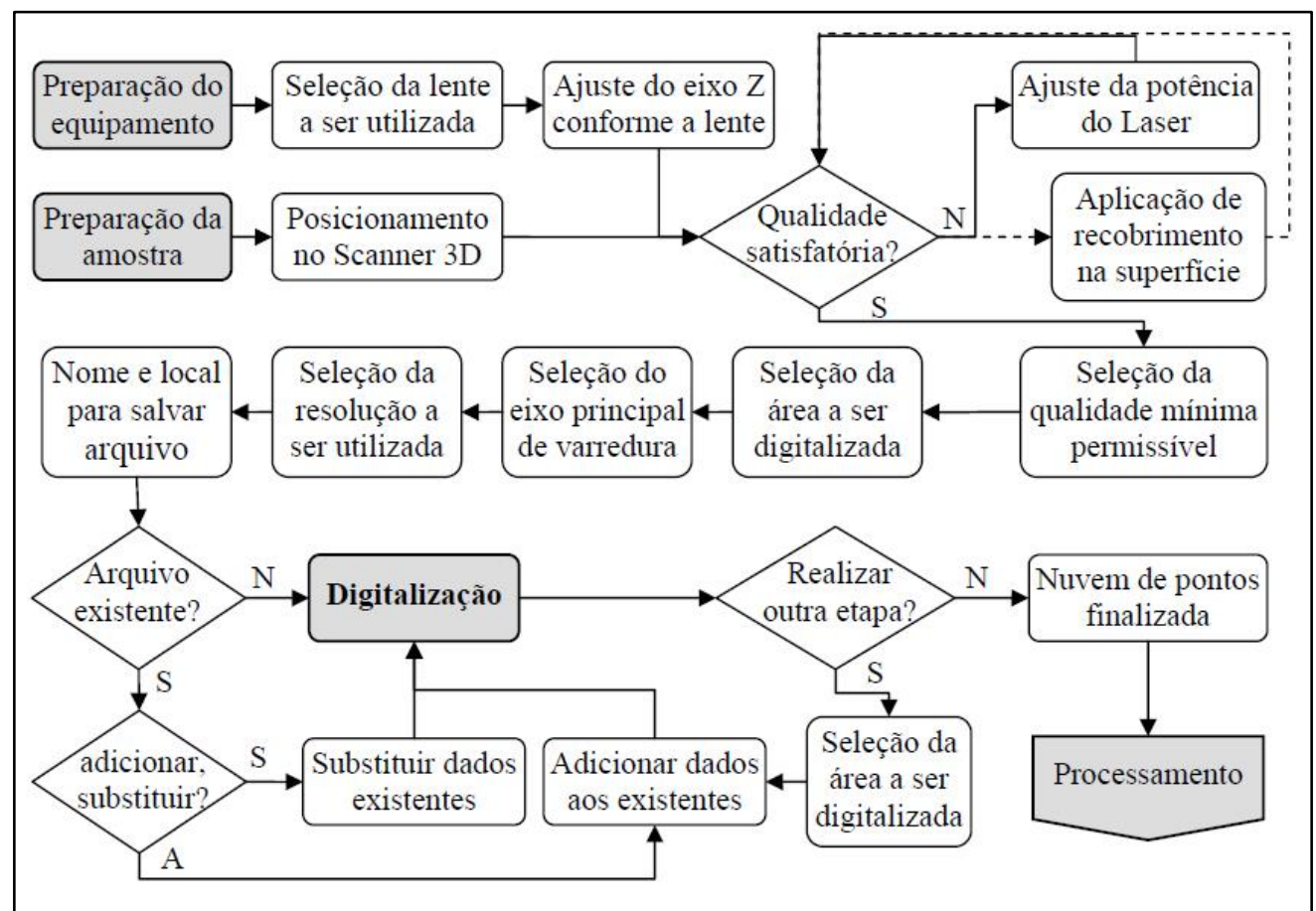

Figura 2 - Procedimentos para a digitalização tridimensional a Laser de uma superfície. Fonte: Silva (2006)

A resolução da varredura, que significa o espaçamento entre os pontos, deve ser ajustada conforme as necessidades do projeto. Neste trabalho, utilizou-se a resolução de 0,2 $\mathrm{mm}$, já que não havia o interesse de digitalizar totalmente a textura do objeto, mas sim, captar sua forma e volume. A Figura 3 apresenta a varredura sendo realizada no equipamento Digimill 3D e seu processamento no software Geomagic Studio.

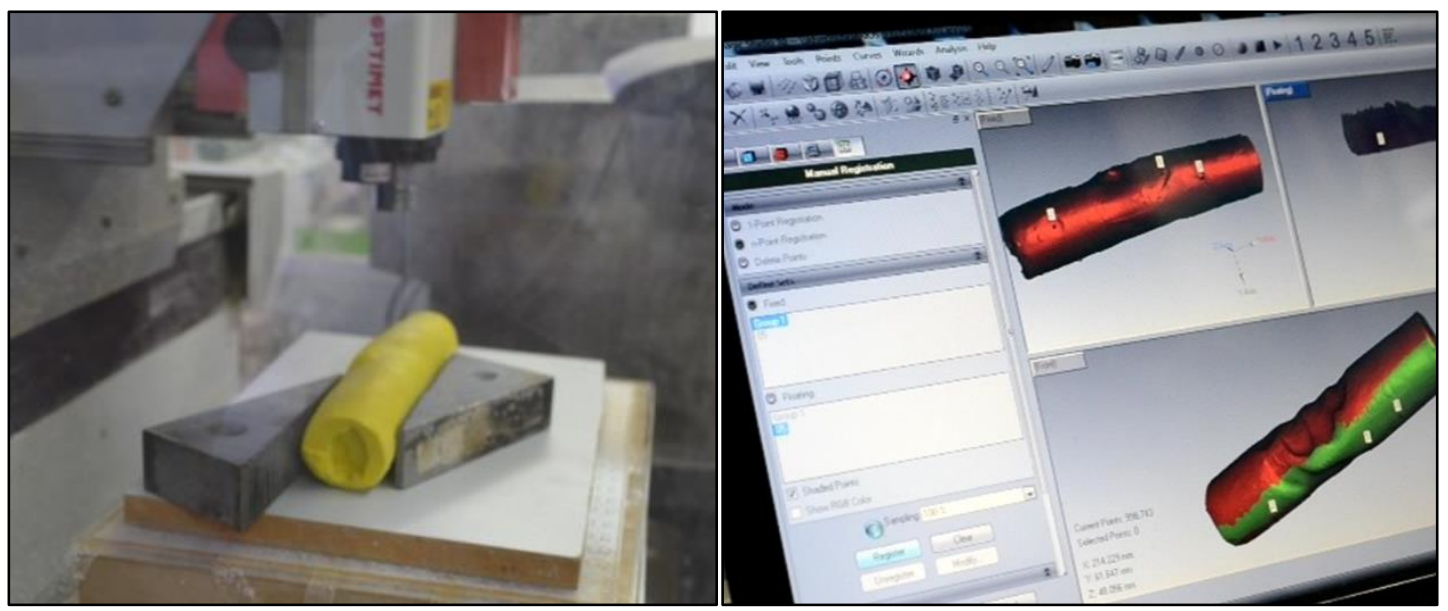

Figura 3 - Massa de modelar sendo digitalizada e união das etapas da superfície digitalizada Fonte: Autor

Além do espaçamento entre os pontos captados, deve-se selecionar a lente adequada. No Laboratório LdSM são usadas seis lentes, de 25, 50, 75, 100, 150 e 250 $\mathrm{mm}$, as quais quanto menores as faixas de trabalho, maior a resolução da lente. Neste trabalho foi utilizada a lente de $100 \mathrm{~mm}$, para que todo o objeto pudesse ser digitalizado em sua faixa de trabalho. Para ajustar o cabeçote à faixa de operação é 
necessário posicioná-lo em uma altura adequada sobre a peça através do eixo $Z$, que neste caso foi de $38 \mathrm{~mm}$. É importante, também, que o material a ser digitalizado tenha uma superfície adequada com relação à opacidade e à cor. Quanto mais escura a superfície (maior absorção) ou mais polida (maior reflexão) maior tende a ser a potência necessária.

Para a digitalização, a massa de modelar foi posta horizontalmente, e foram feitas 5 etapas de captura para que fosse gerada a nuvem de pontos. 0 tempo de cada varredura foi de aproximadamente 10 minutos, totalizando cerca de 50 minutos para todo o processo. A combinação das vistas digitalizadas foi realizada com o uso do software Geomagic Studio, assim como a filtragem e geração da malha de triângulos.

\subsection{Homogeneização da malha}

Após a obtenção dos pontos pela digitalização é importante avaliar a qualidade da malha gerada para possíveis modificações de geometria em CAD (Computer Aided Design). Para Freitas (2006), o resultado de uma digitalização depende principalmente da qualidade do equipamento de digitalização, da preparação da amostra e das condições externas como temperatura, vibrações, luminosidade, etc. Silva (2006) ressalta que por mais controlado que seja o processo, sempre haverá ruídos elétricos ou mecânicos, os quais causarão distorções indesejadas na nuvem de pontos, por isso, foi necessária a homogeneização da malha do objeto.

Após a nuvem de pontos ter sido filtrada, e também após a criação da malha tridimensional da superfície da peça, o arquivo foi salvo no formato STL (STereoLithography), que é o formato padrão utilizado na indústria para os sistemas de prototipagem rápida. Este formato foi aberto no software 3D Studio Max para ser convertido em Object File para que, desta forma, pudesse ser alterado no software Z Brush. Este último é um software para trabalho com modelos digitais que utiliza o princípio de escultura digital, ao invés da edição poligonal através dos vértices, tornando-se de fácil uso e produção.

Desta forma, foi possível preencher facilmente as imperfeições geradas na superfície, por exemplo, pelo suporte que fixava a massa de modelar na faixa de trabalho da lente do equipamento Digimill 3D. Além disso, a massa de modelar já apresentava algumas rupturas devido à evaporação da umidade presente em seu interior, o que ocasionou na digitalização indesejada destas rachaduras.

Após os ajustes na superfície necessários, o arquivo foi novamente importado para o software 3D Studio Max para poder ser convertido em STL, afim de, posteriormente, ser usinado em madeira na máquina CNC.

\subsection{Usinagem CNC}

Para processos de produção com produtos altamente personalizados é necessário desenvolver um alto nível de flexibilidade, reorganizando as estruturas das atividades na produção e distribuição destes produtos (MOURTZIS et al. 2008, apud. BERETTA, 2011). Os processos automatizados, como a usinagem CNC, podem trazer agilidade em sistemas produtivos personalizados já que é possível produzir diferentes produtos na mesma máquina, desde que cada um tenha uma programação específica (BERETTA, 2011).

A usinagem é definida como um processo de fabricação utilizado para dar forma a um componente através da remoção de material. O fresamento é um dos 
processos mais utilizados dentro da usinagem, o qual consiste em uma ferramenta cortante que faz um movimento de rotação e movimentos de translação sobre a peça. Segundo Silva (2011) este processo é utilizado, por exemplo, para produzir moldes para injeção de plástico. Porém, para pequenos lotes, este mesmo processo pode eliminar o uso de moldes, usinando diretamente em blocos do material desejado, mas, para isso, cada material requer um parâmetro de usinagem específico.

Neste trabalho, foi usinada uma chapa de MDF com espessura de 30 milímetros. Antes da programação da usinagem foi necessário dividir a peça ao meio em software CAD após a digitalização tridimensional. Desta forma, foi possível usinar lado a lado toda a superfície do objeto sem a necessidade de rotacionar a chapa de MDF.

Antes da usinagem é necessário programar o processo determinando o tipo de ferramenta (fresa) a ser utilizada, bem como os parâmetros de corte, velocidade de rotação, velocidade de avanço, penetração de trabalho e profundidade de corte. Desta forma, esta programação foi realizada no software Artcam. Para a usinagem, determinaram-se duas etapas, uma primeira de desbaste e uma segunda de acabamento. $O$ desbaste foi realizado com uma fresa reta de 6 milímetros de diâmetro que removeu a maior parte do material existente. Este material removido é chamado de cavaco, e o resultado final da primeira etapa de usinagem é a peça usinada semelhante a curvas de nível, pronta para receber o acabamento. A Figura 6 mostra o desbaste realizado e a produção do cavaco ao redor da peça e o seu acabamento.

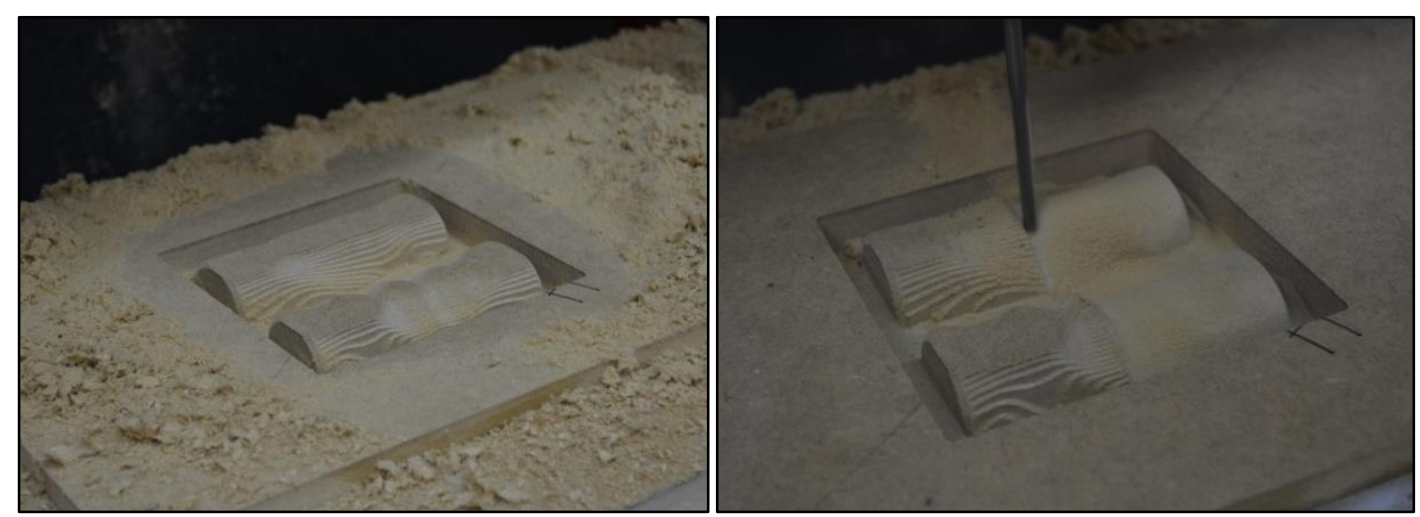

Figura 6 - Etapa de desbaste (esquerda) e de acabamento (direita) Fonte: Autor

O acabamento foi realizado com uma fresa esférica igualmente de 6 milímetros de diâmetro. Nesta etapa, a peça é refinada para possuir as medidas exatamente idênticas às apresentadas anteriormente pela digitalização. Assim, a mesma forma que possuía a massa de modelar, agora também pode ser vista em um material mais rígido como o MDF.

Após a usinagem, os dois lados da pega foram unidos com cola para madeira e posteriormente receberam uma pintura para fins de acabamento estético. A partir deste modelo foi possível, então, realizar a validação do produto junto ao usuário. 0 capítulo a seguir apresenta a validação realizada seguindo a metodologia de Löbach (2001).

\subsection{Validação}


Para realização da validação foi inserida à empunhadura um produto de barbear de cabo estreito. Este cabo é produzido para ser utilizado através do manejo fino, desta forma, a empunhadura antropomórfica produzida neste trabalho substituiu o cabo existente para proporcionar um manejo grosseiro mais firme. Foi feito uma perfuração com uma broca de 10,5 milímetros de espessura para que pudesse encaixar a pega do barbeador na empunhadura. A Figura 8 apresenta a adaptação realizada. Para fins de validação, foi requisitado ao usuário parkinsoniano que realizasse a tarefa de barbear-se. O processo foi analisado de forma assistemática através de documentação fotográfica. As Figuras 9 e 10 exemplificam as imagens coletadas. Podese perceber a notória melhoria na realização da atividade. Através da nova pega, mais ergonômica para as necessidades do usuário, foi possível que ele realizasse a tarefa sem a necessidade de auxílio por outra pessoa. Além disso, o produto tornou-se mais seguro, reduzindo os riscos de lesões devido às lâminas. O único aspecto negativo relatado pelo usuário foi o acréscimo de peso no produto, tornando-o mais fatigante.

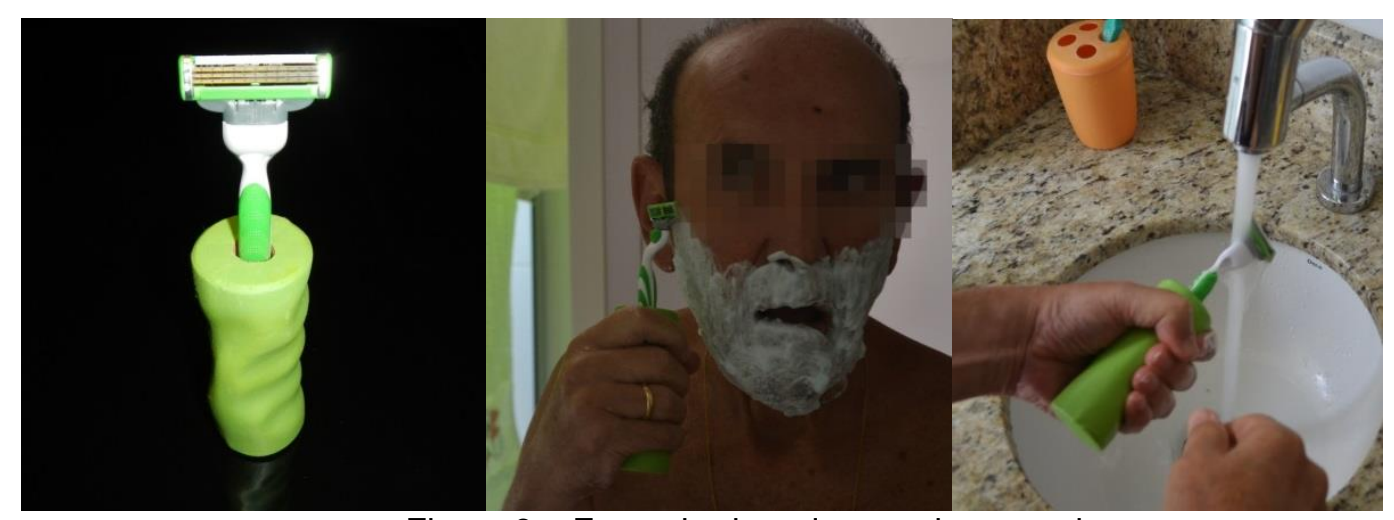

Figura 8 - Empunhadura de manejo grosseiro Fonte: Autor

\section{CONSIDERAÇÕES FINAIS}

Processos inovadores de produção, além de produtos diferenciados, devem ser premissas fundamentais para o profissional de design. Através de um processo de desenvolvimento de produto consistente é possível criar artefatos que auxiliem aos usuários melhorando a sua qualidade de vida. Novas tecnologias como o uso da Digitalização Tridimensional e o processo de produção por usinagem CNC influenciam para o seu uso criativo na solução de problemas de projeto, sendo opções de agilidade, qualidade e inovação.

A digitalização 3D permite o projeto de produtos personalizados, proporcionando a possiblidade de uma personalização em massa. Da mesma forma, esta ferramenta pode contribuir para o projeto de produtos voltados à tecnologia assistiva. A usinagem em CNC, vastamente utilizada em outras aplicações, como na produção de matrizes de injeção de polímeros, aqui, é utilizada de forma diferenciada, produzindo diretamente um produto pronto para ser comercializado.

É importante salientar que este trabalho não tem como objetivo apresentar uma solução final de produto, mas sim, demonstrar o uso de novas tecnologias em prol de projetos diferenciados. Desta forma, este trabalho abre espaço para novas pesquisas futuras, como, por exemplo, o uso de diferentes materiais para a empunhadura, já que a produzida em madeira neste trabalho é pouco tolerante ao contato com água. 
Por fim, este projeto pode ser expandido para outras diversas aplicações, tanto de funcionalidade do produto, como talheres, bengalas, escovas de dente, ou qualquer produto que possua empunhadura, quanto, também, para diferentes tipos de usuários. Pode-se imaginar em um futuro próximo, a produção de empunhaduras personalizadas para policiais, que necessitam o uso constante de armas precisas e que estão sujeitos ao estresse de suas funções. Outro exemplo pode ser aplicado a esportistas de alta performance, os quais necessitam de pegas antropomórficas, a fim de potencializar seus rendimentos em provas de competição.

\section{REFERENCIAS}

BERETTA, E. M. Tecnologia Assistiva: Personalização em Massa através do Design e Fabricação de Assentos Customizados para Cadeiras de Rodas. Dissertação de Mestrado. PGDESIGN, UFRGS, Porto Alegre, 2011.

FREITAS, Gustavo. Metodologia e aplicabilidade da digitalização 3D a laser no desenvolvimento de moldes para calçados e componentes. Dissertação de mestrado, PPGEM/UFRGS. Porto Alegre: Universidade Federal do Rio Grande do Sul, 2006.

IIDA. I. Ergonomia: Projeto e Produção. 2 ed. São Paulo: Edgard Blücher, 1998.

GRANT. A. K., HABES J. D., AND STEWARD. L. L. An analysis of handle designs for reducing manual effort: The influence of grip diameter. Internacional Journal of Industrial Ergonomics, 1992.

KONG. Y., FREIVALDS. A., AND KIM. S. E. Evaluation of handles in a maximum gripping task. Taylor\&Francis Healthsciences Journal. 2004.

LEITE, M. C. P. Doença de Parkinson. Departamento de Informática Médica - Hospital Policlin. Disponível em:< http://www.doencadeparkinson.com.br/dpdefinicao.htm>. Acessado em: 15/11/2012.

LÖBACH. B. Design Industrial: bases para a configuração dos produtos. São Paulo: Edgard Blücher, 2001.

REIS, T. Doença de Parkinson: Busca da Qualidade de Vida. Porto Alegre: Imprensa Livre, 2012.

RIBEIRO, M. A.; GOUVINHAS, R. P.; ROMEIRO FILHO, E. O design universal como abordagem ergonômica na concepção de produtos, 2001. Trabalho apresentado ao $3^{\circ}$ Congresso Brasileiro de Gestão de Desenvolvimento de Produto, Florianópolis, 2001.

SILVA, F. P. O uso da Digitalização Tridimensional a Laser no Desenvolvimento e Caracterização de Texturas Aplicadas ao Design de Produtos. Dissertação de Mestrado. PPGEM, UFRGS, Porto Alegre, 2006. 
SILVA, F. P. Usinagem de Espumas de Poliuretano e Digitalização Tridimensional para Fabricação de Assentos Personalizados para Pessoas com Deficiência. Tese de Doutorado. PPGEM, UFRGS, Porto Alegre, 2011.

TILLEY, A. R. As medidas do homem e da mulher: fatores humanos em design. Porto Alegre: Bookman, 2005. 